\title{
Acoustic behaviour of the European spiny lobster Palinurus elephas
}

\author{
G. Buscaino ${ }^{1, *}$, F. Filiciotto ${ }^{1}$, M. Gristina ${ }^{2}$, A. Bellante ${ }^{1}$, G. Buffa ${ }^{1}$, V. Di Stefano ${ }^{1}$, \\ V. Maccarrone ${ }^{1}$, G. Tranchida ${ }^{1}$, C. Buscaino ${ }^{1}$, S. Mazzola ${ }^{1}$ \\ ${ }^{1}$ Istituto per l'Ambiente Marino Costiero U.O.S. Capo Granitola - Consiglio Nazionale delle Ricerche, Via del Faro No. 3, \\ 91021 Granitola, TP, Italy \\ ${ }^{2}$ Istituto per l'Ambiente Marino Costiero U.O.S. Mazara del Vallo — Consiglio Nazionale delle Ricerche, \\ Via L. Vaccara No. 61, 91026 Mazara del Vallo, TP, Italy
}

\begin{abstract}
The acoustic behaviour of the European spiny lobster Palinurus elephas (Fabricius, 1787) was examined in the absence or presence of predators or conspecifics. Observations were conducted in a tank equipped with digital video and acoustic monitoring and recording systems using 25 adult lobsters and 5 common octopuses Octopus vulgaris. Single lobsters or groups of 4 lobsters were studied for $2 \mathrm{~h}$. These were left alone during the first hour and exposed to a single specimen of the common octopus during the second hour. The lobsters' signals were acoustically analysed. Signal duration, number of pulses per signal, pulse rate, bandwidth, peak intensity, and peak frequency were measured. Single lobsters emitted a higher number of signals than lobsters belonging to a group. The signal (rasp) was audible to humans only in the presence of a predator and was always associated with specific behavioural events. In the absence of a predator, the lobsters produced ultrasound signals (screech) having lower duration, number of pulses per signal, bandwidth, and peak intensity and higher pulse rate and peak frequency. Audible rasps were produced in an anti-predator context, whereas the ultrasound screeches were also emitted under non-stressful conditions. Thus, these signals may play a role in intraspecific communication.
\end{abstract}

KEY WORDS: Acoustic behaviour · Palinurus elephas $\cdot$ Intraspecific communication · Antipredator behaviour Resale or republication not permitted without written consent of the publisher

\section{INTRODUCTION}

Spiny lobsters (Palinuridae), like other arthropods, produce acoustic signals (Moulton 1957, MeyerRochow \& Penrose 1974, Patek 2002, Patek \& Oakley 2003, Patek \& Baio 2007, Bouwma \& Herrnkind 2009, Patek et al. 2009). The sound is produced by a specialised stridulating organ composed of 2 parts: a movable plectrum attached to the last segment of the antennal peduncle and a rigid file (Meyer-Rochow \& Penrose 1974, 1976, Patek 2002, Patek \& Oakley 2003, Patek \& Baio 2007). This organ is located at the base of the long second antenna, which is also the lobster's primary defensive weapon (Patek 2002). The lobster draws the plectrum up the file by moving the antenna base posteriorly to produce sound. Friction between the soft underside of the plectrum and the anteriorly projecting scales of the file causes the moving plectrum to alternately stick and slip, producing a pulse of sound with each slip (MeyerRochow \& Penrose 1974, 1976, Patek 2001, 2002). Some authors have assumed that lobsters only produce sounds in an anti-predator context (Lindberg 1955, Moulton 1957, Hazlett \& Winn 1962, Takemura 
1971, Meyer-Rochow \& Penrose 1974, 1976, Smale 1974, Mulligan \& Fischer 1977, Patek 2001, 2002, Bouwma \& Herrnkind 2009, Patek \& Oakley 2003, Patek et al. 2009, Staaterman at al 2010). Although various functional hypotheses for distress calls in other animals in anti-predator contexts have been suggested (Smith 1986, Driver \& Humphries 1988, Klump \& Shalter 1984), the role of lobsters' stridulation and the potential receivers remain unclear.

The European spiny lobster Palinurus elephas (Fabricius, 1787) is common along the Mediterranean and northeastern Atlantic coasts (Hunter 1999, Ceccaldi \& Latrouite 2000). This species, which is primarily active at night, lives between the shore and a depth of $200 \mathrm{~m}$ on rocky and coralligenous substrates where micro-caves, crevices and natural holes are available (Ceccaldi \& Latrouite 2000).

Palinurus elephas emits acoustic signals termed rasps (Patek \& Oakley 2003). The rasp duration, number of pulses per rasp and pulse rate have only been assessed after stress caused by human manipulation, and the spectral characteristics of the rasp were not studied (Patek \& Oakley 2003). Moreover, studies on the production of sound by spiny lobsters have primarily focussed on the audible range, and information on acoustic emissions under different ecological conditions remains rare and fragmentary (Patek \& Oakley 2003, Buscaino et al. 2011, Staaterman et al. 2010). Information about the context in which lobsters emit acoustic signals is important because it allows improved knowledge of the ecological role of these signals. Moreover, the acoustic parameters that characterise the signals could provide valuable information. For example, the energy distribution at different frequencies could indicate species that are potentially able to perceive the signals if the audiogram of these species is known. The power of the signal reveals its spatial range before it is lost in the undersea background noise. Moreover, if the signals are emitted in the absence of predators, a wider role for these signals could be hypothesised in addition to an anti-predator function.

To understand the ecological meaning of the production of sound by spiny lobsters, we conducted outdoor arena experiments to examine the acoustic signals under different conditions (alone, in the presence of conspecifics, or in the presence of a predator). The goals of the study were to characterise the acoustic signals emitted by European spiny lobsters and to determine whether their number and structure depended on the presence of conspecifics, the presence of a predator (Octopus vulgaris), or the ongoing behaviour of the lobster.

\section{MATERIALS AND METHODS}

\section{Collection and housing of animals}

The study was performed at the Capo Granitola/ CNR laboratory (SW Sicily) from May through June 2009. Twenty-five adult European spiny lobsters Palinurus elephas (17 males and 8 females) weighing $193 \pm 55 \mathrm{~g}$ and $183 \pm 26 \mathrm{~mm}$ in total length (mean \pm SD), respectively, and 5 adult common octopuses Octopus vulgaris weighing $1656 \pm 168 \mathrm{~g}$ (mean $\pm \mathrm{SD}$ ) were used. All animals were captured between January and February 2008. The European spiny lobsters were captured at a depth of 20 to $25 \mathrm{~m}$ near Isola delle Femmine (NW Sicily) by fishermen using a commercial trammel net (54-mm inner-panel mesh size, $1200 \mathrm{~m}$ length). The individuals were transferred to 2 shaded outdoor PVC circular tanks $(3.0 \mathrm{~m}$ diameter) supplied with a thin layer of sand approx. $1 \mathrm{~cm}$ deep. The common octopuses were caught using trammel nets by a commercial fishery at the same location and depths used to capture the lobsters. In the laboratory, the octopuses were kept in an outdoor PVC circular tank (3.0 m diameter) supplied with a thin layer of sand approx. $1 \mathrm{~cm}$ deep. The temperature and salinity levels were monitored using a multiparametric probe (EC300, VWR International) and were kept constant, at $19.3 \pm 0.78^{\circ} \mathrm{C}($ mean $\pm \mathrm{SD})$ and $35.4 \pm 0.81$ ppt (mean $\pm \mathrm{SD}$ ), with a constant flow of seawater provided at a rate of $25 \pm 3.71 \mathrm{~min}^{-1}$ (mean $\pm \mathrm{SD}$ ). The tanks were covered with a dark cloth to reduce the light intensity. The lobsters were fed crabs and frozen shrimps ad libitum. The octopuses were fed shrimps and frozen fish (Boops boops) ad libitum. The lobsters and the octopuses were deprived of food for $5 \mathrm{~d}$ before the start of the experimental trials. All animals were kept under natural photoperiods.

The protocols of animal husbandry and experimentation were reviewed and approved in accordance with recommended standards (NRC 1996) and EEC Directive 86/609.

\section{Rationale and experimental procedures}

We carried out all the experiments in the afternoon (at approx. 17:00 h), and completed them before sunset (20:00 h). The lobsters, individually or in groups of 4 individuals, were randomly collected from the holding tanks, assigned to the trials and used in one experiment only to meet the assumption of experimental independence. Each individual predator was 
used twice. The lobsters (individually or in groups) were released into the centre of the experimental tank. No shelter was present in the tank. The trial started after $1 \mathrm{~h}$ of habituation. After this habituation period and in the absence of any predator, the lobster's acoustic signals were monitored and recorded for $1 \mathrm{~h}$ (no-predator trials). A predator was then released into a small cylindrical tank $(80 \mathrm{~cm}$ diameter, $40 \mathrm{~cm}$ height) in the centre of the arena. After $10 \mathrm{~s}$, the tank was removed, leaving the predator in the arena. The lobster's acoustic behaviour (individually or in groups) was monitored and recorded for an additional $1 \mathrm{~h}$ (predator trials).

To assess the differences in the number and in the characteristics of the acoustic signals emitted by Palinurus elephas, we analysed the acoustic behaviour of lobsters under different conditions. Overall, we performed 20 trials: a single lobster (no stimuli/stress: $\mathrm{n}=5$ trials), grouped lobsters (only conspecific stimuli/stress: $\mathrm{n}=5$ trials), a single lobster with a predator (predation stimuli/stress: $\mathrm{n}=5$ trials), and grouped lobsters with a predator (conspecific stimuli/stress and predation stress: $\mathrm{n}=5$ trials). The synchronised audio-video system also recorded the behaviour of the lobsters visually (Buscaino et al. 2011) and permitted us to characterise and define the acoustic signals produced in association with particular behavioural events.

\section{Acoustic and video monitoring system and analysis}

To avoid disturbing the animals inside the experimental tank, a laboratory enclosure was placed $5 \mathrm{~m}$ from the tank and the equipment required for audiovideo monitoring and recording installed there. The acoustic signals emitted by the lobsters were recorded using a calibrated hydrophone (model 8104, Bruel \& Kjer) with a sensitivity of $-205.6 \mathrm{~dB}$ re $1 \mathrm{~V} / \mu \mathrm{Pa} \pm 4.0 \mathrm{~dB}$ in the $0.1 \mathrm{~Hz}$ to $80 \mathrm{kHz}$ frequency band. The hydrophone was used with a preamplifier (VP1000, Reson), $1 \mathrm{MHz}$ bandwidth single-ended voltage, with the high-pass filter set at $10 \mathrm{~Hz}$ with a $32-\mathrm{dB}$ gain. The equipment was connected to a digital acquisition card (USGH416HB, Avisoft Bioacoustics, septate with no gain) managed by dedicated Avisoft Recorder USGH software (Avisoft Bioacoustics).

The signals were acquired at 300 kilosamples s ${ }^{-1}$ at 16 bits and analysed by the Avisoft-SASLab Pro software (Avisoft Bioacoustics). The digital acquisition card was calibrated with pure tone sine waves at different frequencies $(0.2,1$, and $50 \mathrm{kHz})$ with different intensities (peak-to-peak 0.1 and $0.5 \mathrm{~V}$ ) produced by a signal generator (AGILENT 33220) using the SASLab Pro software.

Signals from another hydrophone (Model 8104, Bruel \& Kjer) connected to a preamplifier (VP1000, Reson, $1 \mathrm{MHz}$ bandwidth single-ended voltage) and from 2 cameras were synchronised, digitised, and stored using a DAQ card (Model DV-RT4 Real Time, D-Vision) managed by custom-written software (Model DSE, D-Vision). This audio-video system was used to monitor the lobsters' and predators' behaviour and was synchronised with the system used to record the acoustic signals.

Owing to the reverberation produced by the walls of the tank and by the water surface, we conducted some additional acoustic measurements in open water to assess the possible influence of reverberation on the acoustic parameters. After the end of the trials, we recorded the acoustic signals of 2 lobsters, both in the tank and in a sea cage located in a circular natural harbour (with a diameter of approx. $200 \mathrm{~m}$ and a depth of $3 \mathrm{~m}$ ). A stick was used to deliver a stressful stimulus. We measured the signal duration, pulse duration, number of pulses per signal, pulse rate, peak frequency, peak amplitude and bandwidth for the 'sea signals' and the 'tank signals'. The analysis revealed that the pulse duration, peak amplitude and bandwidth differed between the sea signals and the tank signals (Fig. 1). The reverberation in the tank prolonged the duration of the pulse and increased the peak intensity and bandwidth (Fig. 1b,c; see the area enclosed in a red rectangle).

The pulse duration could not be measured adequately in the tank because the reverberation of the first pulse overlapped with the second pulse. The pulse duration was therefore omitted from further analysis. We included measurements of the peak intensity and the bandwidth because we expected that these parameters would be affected much less strongly by reverberation than by the experimental conditions (the presence or absence of stimuli produced by a conspecific or a predator). These parameters would therefore offer additional information on the acoustic behaviour of the lobster. The analysis therefore included the rasp duration, number of pulses per rasp, pulse rate, peak frequency (the frequency of the maximum of the power spectrum), peak amplitude (the amplitude of the peak frequency) and the bandwidth (the difference between the maximum and the minimum frequencies, calculated relative to the level of the background noise and the inconspicuous signal-frequency limits appearing on the spectrogram). 

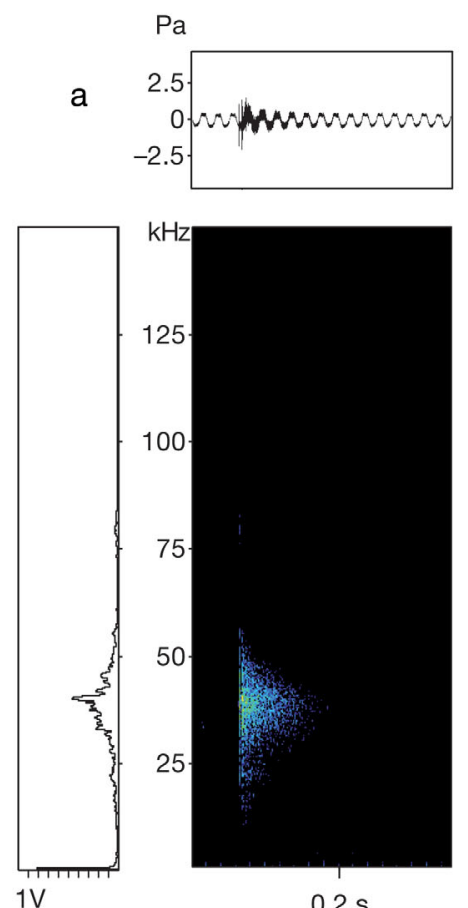

$0.2 \mathrm{~s}$
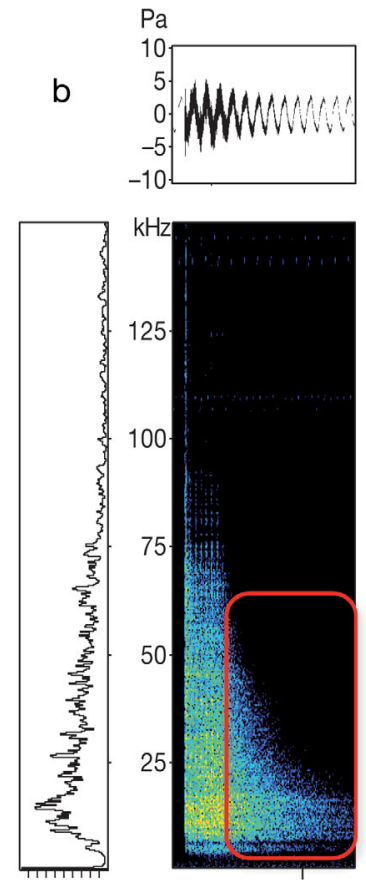

$1 \mathrm{~V}$

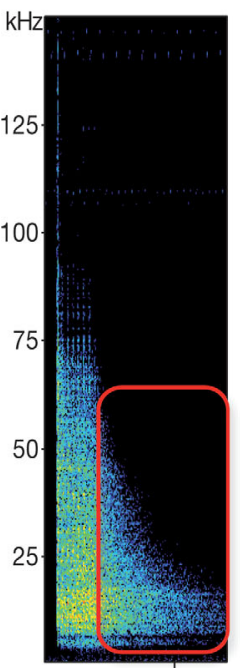

$0.2 \mathrm{~s}$
C
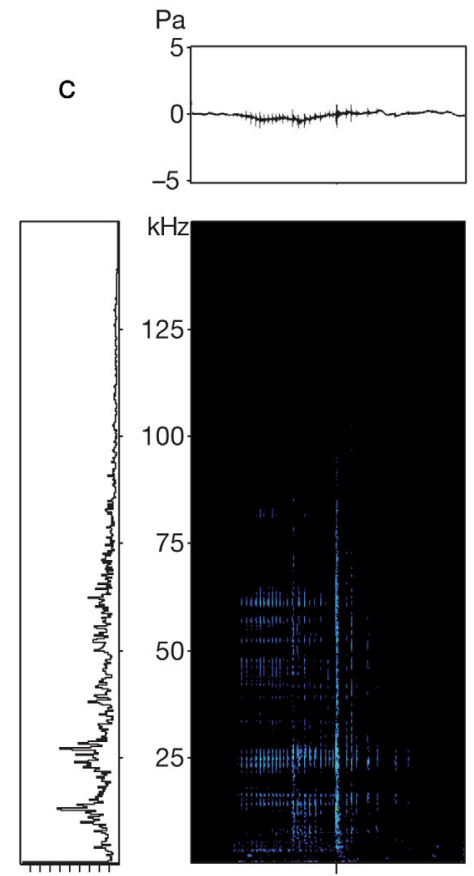

$1 \mathrm{~V}$

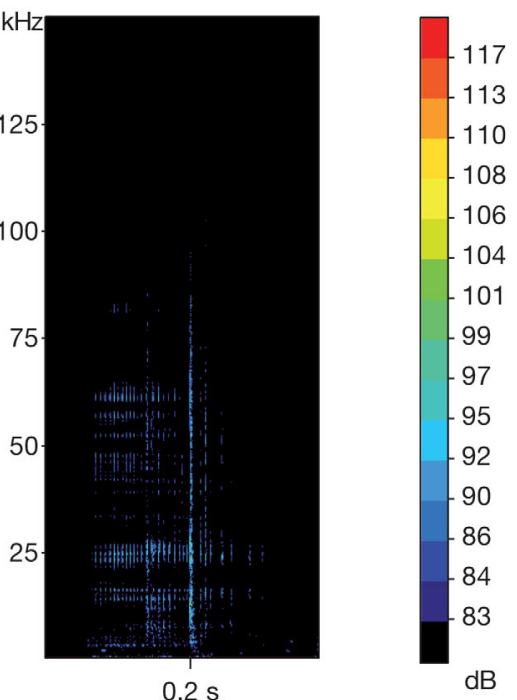

Fig. 1. Palinurus elephas. (a) Ultrasound screech (tank recording). (b) Audible rasp (tank recording). (c) Audible rasp (openharbour recording). Oscillogram (top), maximum power spectrum (left), and spectrogram (right) of spiny lobster signals emitted $1 \mathrm{~m}$ from hydrophone. Oscillograms show pressure (Pa) vs. time (s). Maximum power spectra show frequency (kHz) vs. relative amplitude (V). Spectrograms show frequency $(\mathrm{kHz})$ vs. time $(\mathrm{s})$, with intensity in $\mathrm{dB}$ re $1 \mu \mathrm{Pa}$ on colour scale, 1024-sample Hanning window

We used the Kruskal-Wallis test to assess the differences between the numbers of acoustic signals emitted by the lobsters under different conditions $(1-\mathrm{a}$ single lobster, 2 - grouped lobsters, 3 - a single lobster with a predator, 4-grouped lobsters with a predator). We used the Mann-Whitney $U$-test to detect differences between the parameters of the acoustic signals emitted by the lobsters in association with anti-predator behaviour and in the absence of anti-predator behaviour.

\section{RESULTS}

Overall, 452 signals were recorded during the trials. The mean numbers of the lobsters' acoustic signals under different conditions are shown in Table 1. In the presence of an octopus, the lobsters, both individually and in groups, produced more signals than in the trials without an octopus (Kruskal-Wallis, p < 0.05). In the trials without an octopus, no significant difference was observed between the mean numbers of signals produced by the grouped lobsters and by a single lobster (Kruskal-Wallis, p > 0.05). However, in the grouped lobsters, the mean number of signals
Table 1. Palinurus elephas. Mean number ( \pm standard deviation) of acoustic signals produced by the lobsters under different conditions

\begin{tabular}{|lrc|}
\hline \multirow{2}{*}{ Condition } & \multicolumn{3}{c|}{ No. of acoustic signals } \\
& Without an octopus & With an octopus \\
\hline Single lobster & $12.8( \pm 7.7)$ & $21.8( \pm 10.5)$ \\
Grouped lobster & $8.4( \pm 2.9)$ & $47.4( \pm 12.2)$ \\
Per individual in group & $2.1( \pm 0.7)$ & $11.9( \pm 3.1)$ \\
\hline
\end{tabular}

produced per lobster was lower than that found for a single lobster (Kruskal-Wallis, $\mathrm{p}<0.05$ ). In the trials with an octopus, no differences were found between the number of signals emitted by the grouped lobsters and by a single lobster (Kruskal-Wallis, p > 0.05).

Significant differences in all of the acoustic parameters were found when all signals emitted in the absence of an octopus were compared with signals emitted with a predator and associated with the antipredator behavioural event (Mann-Whitney U-test, $\mathrm{p}<0.01$ for all parameters) (see Table 2). We noted that in the trials without an octopus, the lobsters produced screeches that were barely audible (domi- 
Table 2. Palinurus elephas. Comparison between the mean of the acoustic characteristics of the audible and ultrasound signals emitted by lobster. The Mann-Whitney $U$-test was used to compare all acoustics parameters (except for pulse rate); ${ }^{*} \mathrm{p}<0.001$

\begin{tabular}{|c|c|c|c|c|c|}
\hline & $\begin{array}{l}\text { Audible rasp } \\
\text { Mean } \pm \text { SD }\end{array}$ & $\begin{array}{l}\text { Ultrasound screech } \\
\text { Mean } \pm \text { SD }\end{array}$ & $\begin{array}{l}\text { Compari } \\
\text { Difference between mean }\end{array}$ & n & $\mathrm{p}$-value \\
\hline Pulse rate, $\mathrm{Hz}$ & $118.2 \pm 54.4$ & $298.9 \pm 115.7$ & 180.64 & & \\
\hline Pulse number per signal, $\mathrm{n}$ & $9.5 \pm 4.5$ & $3.4 \pm 1.3$ & 6.02 & 208 & * \\
\hline Signal duration, s & $0.09 \pm 0.05$ & $0.013 \pm 0.008$ & 0.083 & 20 & * \\
\hline Bandwidth, kHz & $122.9 \pm 23.69$ & $88.6 \pm 23.9$ & 34.3 & 317 & * \\
\hline Peak frequency, $\mathrm{kHz}$ & $19.52 \pm 6.7$ & $34.71 \pm 9.2$ & 15.19 & 197 & * \\
\hline Peak amplitude, dB re $1 \mu \mathrm{Pa}$ & $119.82 \pm 8.44$ & $114.11 \pm 5.94$ & 5.75 & 8919 & * \\
\hline
\end{tabular}

nated by ultrasound frequencies) and without any association with a particular behavioural event. During the trials with an octopus, both the ultrasound screech and the audible rasp were recorded, and the latter were always associated with anti-predator behaviours: tail flip, lunge, parry, whip and point (Buscaino et al. 2011). As shown in Fig. 2, the signals associated with anti-predator events, relative to the other ultrasound signals, had a greater duration, number of pulses, peak amplitude and bandwidth as well as a lower peak frequency and pulse rate.

Fig. 1 shows examples of the ultrasound signal and of the audible rasps produced during the trials in the tank. Most of the energy of the ultrasound signals was concentrated in the $20-55 \mathrm{kHz}$ range, whereas the energy of the more powerful audible rasps was concentrated in the $2-75 \mathrm{kHz}$ range, with the peak frequency of $15 \mathrm{kHz}$.

\section{DISCUSSION}

The acoustic signals of spiny lobster species from several areas of the world are known (Moulton 1957, Meyer-Rochow \& Penrose 1974, 1976, Patek 2001, 2002, Patek \& Oakley 2003, Bouwma \& Herrnkind 2009). However, little information is available to characterise the rasps emitted by Palinurus elephas. Patek \& Oakley (2003) assessed the duration, the number of pulses and the pulse rate for the rasp, but they provided no information about the spectral characteristics of the signal. The possible influence of different ecological conditions on the signals is not known because previous studies only focused on acoustic signals produced after the lobsters had been handheld (Patek \& Oakley 2003, Patek et al. 2009).

The acoustic signals produced by Palinurus elephas under different conditions all consisted of a pulsatile rasp or screech with a variable number of pulses. These signals were similar in structure, but showed different acoustic characteristics. During the
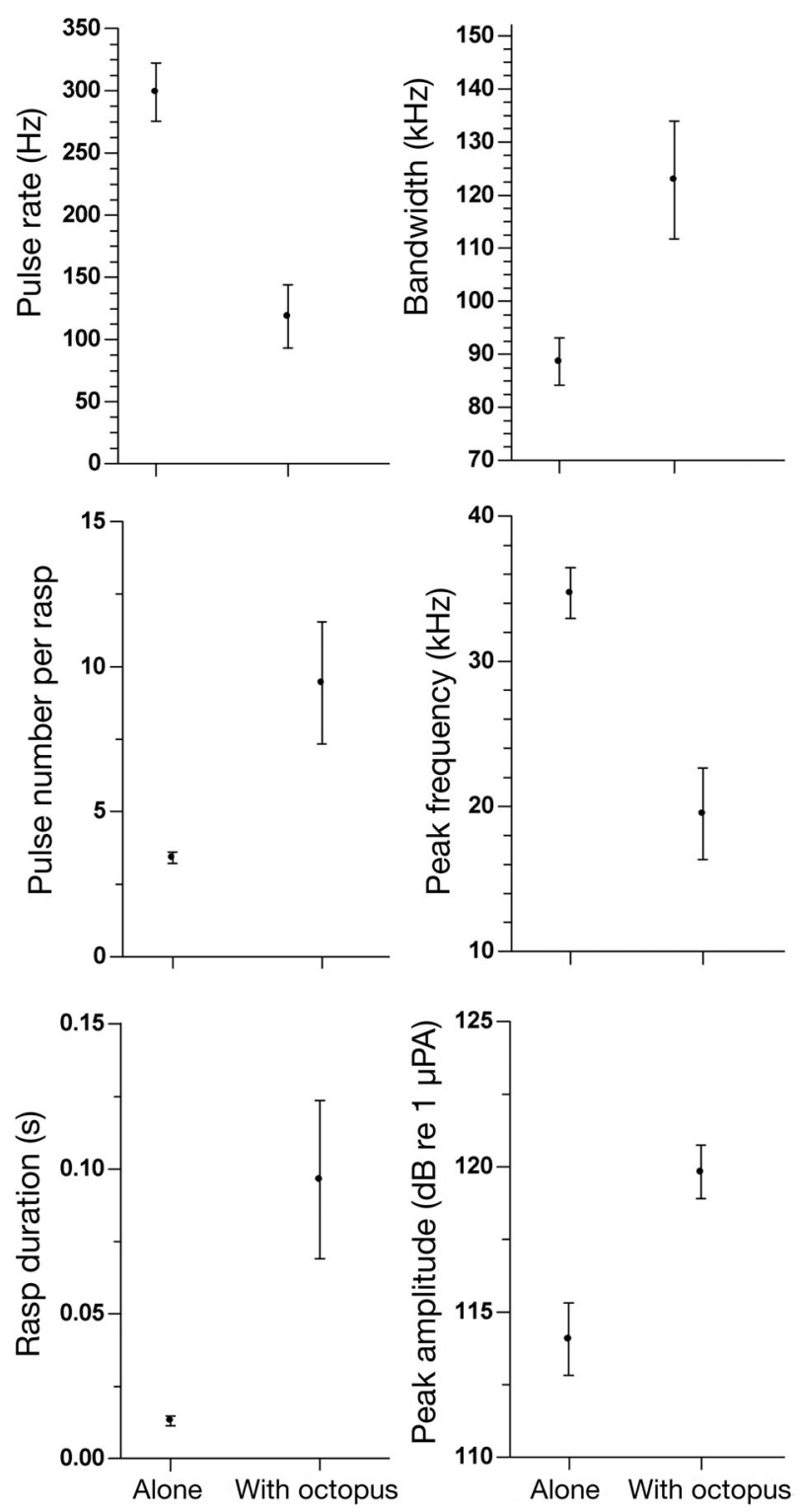

Fig. 2. Palinurus elephas. Means (error bar: $95 \%$ confidence interval) of the acoustic characteristics of the audible rasps emitted by lobsters in the presence of an octopus ('With octopus') and associated with anti-predator behaviour, and of the ultrasound screeches emitted in the absence of a predator

('Alone'; never associated with anti-predator behaviour) 
trials without a predator, the lobster only produced ultrasound screeches, whereas in the presence of a predator, the lobster emitted both ultrasound and audible signals. The audible rasps were characterised by a higher duration, bandwidth, pulse number per rasp and peak amplitude as well as by a lower peak frequency and pulse rate.

We found that the pulse rate of the rasps of Palinurus elephas increased as the number of pulses decreased. These findings are consistent with the results of Patek et al. (2009) for P. interruptus. The mean numbers of pulses and the pulse rates for the ultrasound screeches and for the audible rasps were approx. 3 and $300 \mathrm{~Hz}$, and 9 and $130 \mathrm{~Hz}$, respectively. The latter values are similar to those found by Patek \& Oakley (2003) (13 and 138 Hz, respectively). However, these authors analysed acoustic signals that were produced after the lobsters had been handheld.

The lobsters produced significantly more sounds in the presence of a predator. This result is in agreement with the findings of other authors (Lindberg 1955, Moulton 1957, Hazlett \& Winn 1962, MeyerRochow \& Penrose 1974, 1976, Patek 2001, 2002, Patek \& Oakley 2003, Bouwma \& Herrnkind 2009). These authors assumed that the lobsters only produced sounds in an anti-predator context. Moreover, Bouwma \& Herrnkind (2009) demonstrated that spiny lobsters Panulirus argus with an experimentally disabled stridulating apparatus were attacked and killed by predators more frequently than intact spiny lobsters.

The audible rasp occurs in association with specific anti-predator behaviours (tail flip, lunge, parry, whip and point) (Buscaino et al. 2011) consisting of largeamplitude body movements that significantly affect the movements of the antennae. Various functional hypotheses have been offered as explanations for stridulation in lobsters. These hypotheses include calling for help from conspecifics, alerting conspecifics to danger, attracting another predator that might interfere with the attacker, aposematism, startling the predator, and a reduction in the kinetic friction between the antenna and the predator to facilitate escape (Smith 1986, Driver \& Humphries 1988, Bouwma \& Herrnkind 2009, Staaterman et al. 2010). According to these hypotheses, the lobster, the predator, or a second predator that can potentially interfere with the first predator may be potential targets of the signal. However, the receiver or receivers of the lobster's audible rasps have not yet been identified precisely. The kinetic friction hypothesis is only applicable to cases of direct contact between the predator and lobster. The other predator-related hypotheses seem unlikely because the findings of our study suggest that the octopus is almost unable to hear the rasps. In fact, most of the energy of the rasp was distributed at frequencies higher than $1 \mathrm{kHz}$, whereas the hearing sensitivity of the octopus seems to be limited to lower frequencies (100-200 Hz) (Hanlon \& Budelmann 1987, Williamson 1988, Packard et al. 1990).

Analysis of the power of the signals could help to identify the potential receivers. The peak amplitude of the audible rasps was significantly higher than that of the ultrasound signals. The audible rasps could therefore cover a wider range in the sea and could potentially have receivers in addition to the predator attacking the lobster. These other receivers could be other lobsters or predators of predators. However, the hearing threshold of detection of the potential receivers should be compared to the level of the rasp at different distances from the source of the rasps.

Because the ultrasound screeches were produced without evident movements of the antennae, an additional mechanism to the stick and slip (MeyerRochow \& Penrose 1974, 1976, Patek 2002, 2001, Patek \& Oakley 2003, Patek \& Baio 2007) could be speculated. However, a specific study should be carry out to confirm this hypothesis. The ultrasound screeches were produced both in the presence of the predator and with the predator absent, so that functions in addition to anti-predation could be hypothesised. It should be noted that ultrasound signals had a higher frequency distribution of energy (20-55 kHz) and that lower frequencies, $<5 \mathrm{kHz}$, were not present. This is evidence against the possibility that these signals have lobster predators, such as fish or octopus, as receivers. Moreover, our study found that the number of ultrasound screeches produced was higher for single lobsters than for lobsters in groups. This result allows us to speculate on the potential for intraspecific acoustic communication, because a single lobster could use the ultrasound signal to recruit conspecifics.

The intraspecific communication of European spiny lobster is still hypothetical because the ability of these animals to perceive acoustic signals (including those emitted by conspecifics) has not yet been documented and even the sensitivity of lobsters to different frequencies remains unknown. The mechano-receptors of crustaceans, located in cuticular extensions of the exoskeleton, are called sensilla (Ali 1987) and are able to sense changes in pressure (Ali 1987). Decapod mechanoreceptors include setae (hair-like cells), chordotonal organs, and internal statocysts (Popper et al. 2001). In macruran decapods (crayfish), the hair 
fans are sensitive to vibration (Breithaupt \& Tautz 1990) and can respond to frequencies up to $100 \mathrm{~Hz}$. According to Tautz (1979), hairs of different lengths may be tuned to different frequencies. In other crustaceans, e.g. Palaemon serratus, sensitivity to sounds with frequencies from 100 to $3000 \mathrm{~Hz}$ has been demonstrated (Lovell et al. 2005). Hemisquilla californiensis emitted rumbles for intraspecific communication, with the potential functions of maintenance of territory, or attraction of mates (Staaterman et al. 2011) Thus, the hypothesis that Palinurus elephas is able to perceive intraspecific acoustic signals appears reasonable. However, further studies of this topic should be conducted.

Some acoustic features of a signal could be different in a small tank. For example, Patek et al. (2009) found that the mean first dominant frequency of Palinurus interruptus signals was higher in a tank than in the field (1794 and $633 \mathrm{~Hz}$, respectively). We found that the peak amplitude, the pulse duration, and the bandwidth of the signals were different in the tank, whereas the other parameters remained unchanged. The use of the tank, which is a completely controlled environment, allowed us to discover the previously unknown ultrasound screeches. In the sea, where all of the sources of acoustic signals cannot be known, these ultrasound pulses could not have been attributed to $P$. elephas. A larger tank lined with soundproofing materials would not be subject to reverberation and would allow full control of the experimental variables.

In this study, we characterised the audible rasp both in the frequency and in the time domain. Moreover, we indicated that the European spiny lobster emits the previously undescribed ultrasound screeches in the absence of stress caused by a predator. A single lobster unexposed to a predator produces more ultrasound if it is alone, compared with a lobster in a group. These data, together with the tendency of lobsters to cluster, e.g. during migration (Herrnkind 1969, Herrnkind et al. 1973, Lipcius \& Herrnkind 1985, Herrnkind et al. 2001, Lavalli \& Herrnkind 2009) or as an anti-predator tactic (Herrnkind et al. 2001, Nishimura 2002, Briones-Fourzán et al. 2006, Lavalli \& Herrnkind 2009), could suggest that these animals use acoustic signals in addition to the chemical signals that spread slowly and for short distances (Nevitt et al. 2000, Briones-Fourzán 2009). Acoustic signals may allow lobsters to maintain contact with conspecifics and to use clustering and aggregation as anti-predator tactics (Herrnkind et al. 2001, Barshaw et al. 2003, Briones-Fourzán et al. 2006, Lavalli \& Herrnkind 2009).

\section{LITERATURE CITED}

Ali MA (1987) Nervous systems in invertebrates. Plenum Press, New York, NY

- Barshaw DE, Lavalli KL, Spanier E (2003) Offense versus defense: response of three morphological types of lobsters to predation. Mar Ecol Prog Ser 256:171-182

Bouwma PE, Herrnkind WF (2009) Sound production in Caribbean spiny lobster Panulirus argus and its role in escape during predatory attack by Octopus briareus. NZ J Mar Freshw Res 43:3-13

Breithaupt T, Tautz J (1990) The sensitivity of crayfish mechanoreceptors to hydrodynamic and acoustic stimuli. In: Wiese K, Krenz WD, Tautz J, Reichert H, Mulloney B (eds) Frontiers in crustacean neurobiology. Birkhäuser, Basel, p 114-120

> Briones-Fourzán P (2009) Assessment of predation risk through conspecific alarm odors by spiny lobsters. Commun Integr Biol 2:302-304

Briones-Fourzàn P, Perez-Ortiz M, Lozano-Alvarez E (2006) Defense mechanisms and antipredator behavior in two sympatric species of spiny lobsters, Panulirus argus and P. guttatus. Mar Biol 149:227-239

Buscaino G, Filiciotto F, Gristina M, Buffa G and others (2011) Defensive strategies of European spiny lobster Palinurus elephas during predator attack. Mar Ecol Prog Ser 423:143-154

Ceccaldi HJ, Latrouite D (2000) The French fisheries for the European spiny lobster Palinurus elephas. In: Phillips BF, Kittaka J (eds) Spiny lobster fisheries and culture, 2nd edn. Blackwell, Oxford, p 200-209

Driver PM, Humphries N (1988) Protean behavior: the biology of unpredictability. Oxford University Press, Oxford

Hanlon RT, Budelmann BU (1987) Why cephalopods are probably not 'deaf'. Am Nat 129:312-317

- Hazlett BA, Winn HE (1962) Sound production and associated behavior of Bermuda crustaceans (Panulirus, Gonodactylus, Alpheus, and Synalpheus). Crustaceana 4:25-38

Herrnkind W (1969) Queuing behavior of spiny lobsters. Science 164:1425-1427

Herrnkind WF, Kanciruk P, Halusky J, McLean R (1973) Descriptive characterization of mass autumnal migrations of spiny lobster Panulirus argus. Proc Gulf Caribb Fish Inst 25:79-98

> Herrnkind WF, Childress MJ, Lavalli K (2001) Cooperative defense and other benefits among exposed spiny lobsters: inferences from group size and behaviour. Mar Freshw Res 52:1113-1124

Hunter E (1999) Biology of the European spiny lobster Palinurus elephas (Fabricius, 1787) (Decapoda, Palinuridea). Crustaceana 72:545-565

Klump GM, Shalter MD (1984) Acoustic behaviour of birds and mammals in the predator context; I. Factors affecting the structure of alarm calls. II. The functional significance and evolution of alarm signals. Z Tierpsychol 66:189-226

> Lavalli KL, Herrnkind WF (2009) Collective defense by spiny lobster (Panulirus argus) against triggerfish (Balistes capriscus): effects of number of attackers and defenders. NZ J Mar Freshw Res 43:15-28

Lindberg RG (1955) Growth, population dynamics and field behavior in the spiny lobster, Panulirus interruptus (Randall). Univ Calif Publ Zool 59:157-248

> Lipcius RN, Herrnkind WF (1985) Photoperiodic regulation and daily timing of spiny lobster mating behavior. J Exp Mar Biol Ecol 89:191-204 
Lovell JM, Findlay MM, Moate RM, Yan HY (2005) The hearing abilities of the prawn Palaemon serratus. Comp Biochem Phys A 140:89-100

Meyer-Rochow VB, Penrose JD (1974) Sound and sound emission apparatus in puerulus and postpuerulus of the western rock lobster Panulirus longipes. J Exp Zool 189: 283-289

Meyer-Rochow VB, Penrose JD (1976) Sound production by the western rock lobster Palinurus longipes (Milne Edwards). J Exp Mar Biol Ecol 23:191-209

Moulton JM (1957) Sound production in the spiny lobster Palinurus argus (Latreille). Biol Bull 113:286-295

Mulligan BE, Fischer RB (1977) Sounds and behavior of the spiny lobster Panulirus argus (Latreille, 1804) (Decapoda, Palinuridae). Crustaceana 32:185-199

Nevitt G, Pentcheff ND, Lohmann KJ, Zimmer RK (2000) Den selection by the spiny lobster Panulirus argus: testing attraction to conspecific odors in the field. Mar Ecol Prog Ser 203:225-231

Nishimura SI (2002) A predator's selection of an individual prey from a group. Biosystems 65:25-35

Packard A, Karlsen HE, Sand O (1990) Low frequency hearing in cephalopods. J Comp Physiol A 166:501-505

Patek SN (2001) Spiny lobsters stick and slip to make sound. Nature 411:153-154

Patek SN (2002) Squeaking with a sliding joint: mechanics and motor control of sound production in palinurid lobsters. J Exp Biol 205:2375-2385

Patek SN, Baio JE (2007) The acoustic mechanics of stickslip friction in the California spiny lobster (Panulirus interruptus). J Exp Biol 210:3538-3546

Editorial responsibility: Matthias Seaman, Oldendorf/Luhe, Germany
Patek SN, Oakley TH (2003) Comparative tests of evolutionary trade-offs in a palinurid lobster acoustic system. Evolution 57:2082-2100

Patek SN, Shipp LE, Staaterman ER (2009) the acoustics and acoustic behavior of the California spiny lobster (Palinurus interruptus). J Acoust Soc Am 125:3434-3443

> Popper AN, Salmon M, Horch KW (2001) Acoustic detection and communication by decapod crustaceans. J Comp Physiol A 187:83-89

Smale M (1974) The warning squeak of the Natal rock lobster. S Afr Assoc Mar Biol Res Bull 11:17-19

> Smith RJF (1986) Evolution of alarm signals: role of benefits of retaining group members or territorial neighbors. Am Nat 128:604-610

> Staaterman ER, Claverie T, Patek SN (2010) Disentangling defense: the function of spiny lobster sounds. Behaviour 147:235-258

> Staaterman ER, Clark CW, Gallager AJ, deVries MS, Claverie T, Patek SN (2011) Rumbling in the benthos: acoustic ecology of the California mantis shrimp Hemisquilla californiensis. Aquat Biol 13:97-105

> Takemura A (1971) Studies on underwater sound III. On the mechanism of sound production and the underwater sounds produced by Linuparus trigonus. Mar Biol 9: 87-91

Tautz J (1979) Water vibration elicits oscillations in a medium - an unorthodox sensory capacity. Naturwissenschaften 66:452-461

Williamson R (1988) Vibration sensitivity in the statocyst of the northern octopus, Eledone cirrosa. J Exp Biol 134: $451-454$

Submitted: February 25, 2011; Accepted: September 16, 2011 Proofs received from author(s): November 2, 2011 